\title{
Environmental Risk Assessment System for Phosphogypsum Tailing Dams
}

\author{
Xin Sun, ${ }^{1}$ Ping Ning, ${ }^{1}$ Xiaolong Tang, ${ }^{2}$ Honghong Yi, \\ Kai Li, ${ }^{1}$ Lianbi Zhou, ${ }^{3}$ and Xianmang $\mathrm{Xu}^{1}$ \\ ${ }^{1}$ Faculty of Environmental Science and Engineering, Kunming University of Science and Technology, Kunming 650093, China \\ ${ }^{2}$ Department of Environmental Engineering, University of Science and Technology Beijing, Beijing 100083, China \\ ${ }^{3}$ Beijing General Research Institute of Mining and Metallurgy, Beijing 100160, China \\ Correspondence should be addressed to Ping Ning; ningping1958@163.com
}

Received 2 September 2013; Accepted 20 October 2013

Academic Editors: N. F. Atta and M. Yari

Copyright (C) 2013 Xin Sun et al. This is an open access article distributed under the Creative Commons Attribution License, which permits unrestricted use, distribution, and reproduction in any medium, provided the original work is properly cited.

\begin{abstract}
This paper may be of particular interest to the readers as it provides a new environmental risk assessment system for phosphogypsum tailing dams. In this paper, we studied the phosphogypsum tailing dams which include characteristics of the pollution source, environmental risk characteristics and evaluation requirements to identify the applicable environmental risk assessment methods. Two analytical methods, that is, the analytic hierarchy process (AHP) and fuzzy logic, were used to handle the complexity of the environmental and nonquantitative data. Using our assessment method, different risk factors can be ranked according to their contributions to the environmental risk, thereby allowing the calculation of their relative priorities during decision making. Thus, environmental decision-makers can use this approach to develop alternative management strategies for proposed, ongoing, and completed PG tailing dams.
\end{abstract}

\section{Introduction}

The rapid industrialization in China has consumed vast amounts of various industrial raw materials and large quantities of industrial solid wastes remain from mining, mineral processing, and smelting processes [1]. Thousands of industrial sites are contaminated by industrial waste, which are significant threats to the environment and human health. The production and storage of industrial solid waste have resulted in land contamination and the loss of natural resources, as well as posing significant environmental risks.

Phosphogypsum (PG) is an acidic by-product of the phosphate fertilizer industry, which is produced during the production of phosphoric acid from phosphate rock. Large amounts of PG have been produced around the world and the production will increase to several hundred million metric tonnes annually [2]. Over 60 million tonnes of PG is produced per annum in China, which poses various environmental and storage problems.

Environmental risk assessments are widespread, including ecological, water, soil, and atmospheric environmental risk assessment [3-7]. At present, many experts use sitespecific evaluation criteria and methods to assess different types of environmental risks in different areas, such as mine sites and urban environments. For example, ecological risk assessment guidelines have been enacted by the USA [8]. Health risk assessment has been used to evaluate brownfield sites contaminated by POPs [9]. The establishment of environmental risk assessments started relatively recently in China. At present, many areas are contaminated and serious pollution problems demand environmental risk assessments, such as PG tailing dams. Thus, we studied PG tailing dams, including the characteristics of the pollution sources and the environmental risk characteristics and identified 


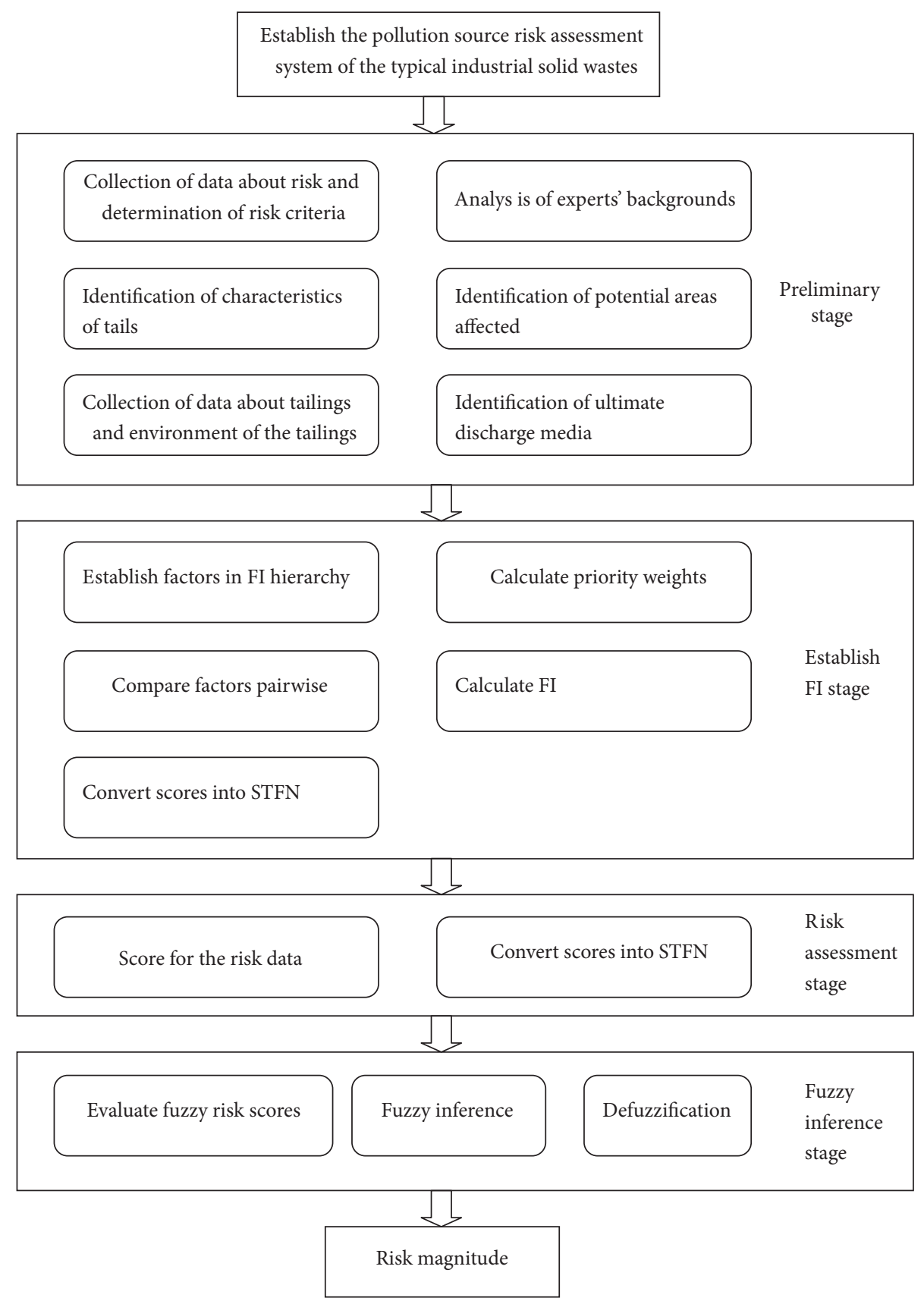

FIGURE 1: Risk assessment approach of the typical staple industrial solid waste (TSISW).

TABLE 1: Scale of relative importance used in the pairwise comparison of AHP.

\begin{tabular}{lcr}
\hline Linguistic variable & $\begin{array}{c}\text { Scale of relative importance } \\
\text { (crisp number) }\end{array}$ & $\begin{array}{c}\text { Trapezoidal fuzzy number } \\
\text { Equally important }\end{array}$ \\
Weakly important & 1 & $(1,1,1,1)$ \\
Essentially important & 3 & $(2,5 / 2,7 / 2,4)$ \\
Very strongly important & 5 & $(4,9 / 2,11 / 2,6)$ \\
Absolutely important & 7 & $(6,13 / 2,15 / 2,8)$ \\
& $x=2,4,6,8$ are intermediate & $(8,17 / 2,9,9)$ \\
& scale & $(x-1, x-1 / 2, x+1 / 2, x+1)$ \\
\hline
\end{tabular}




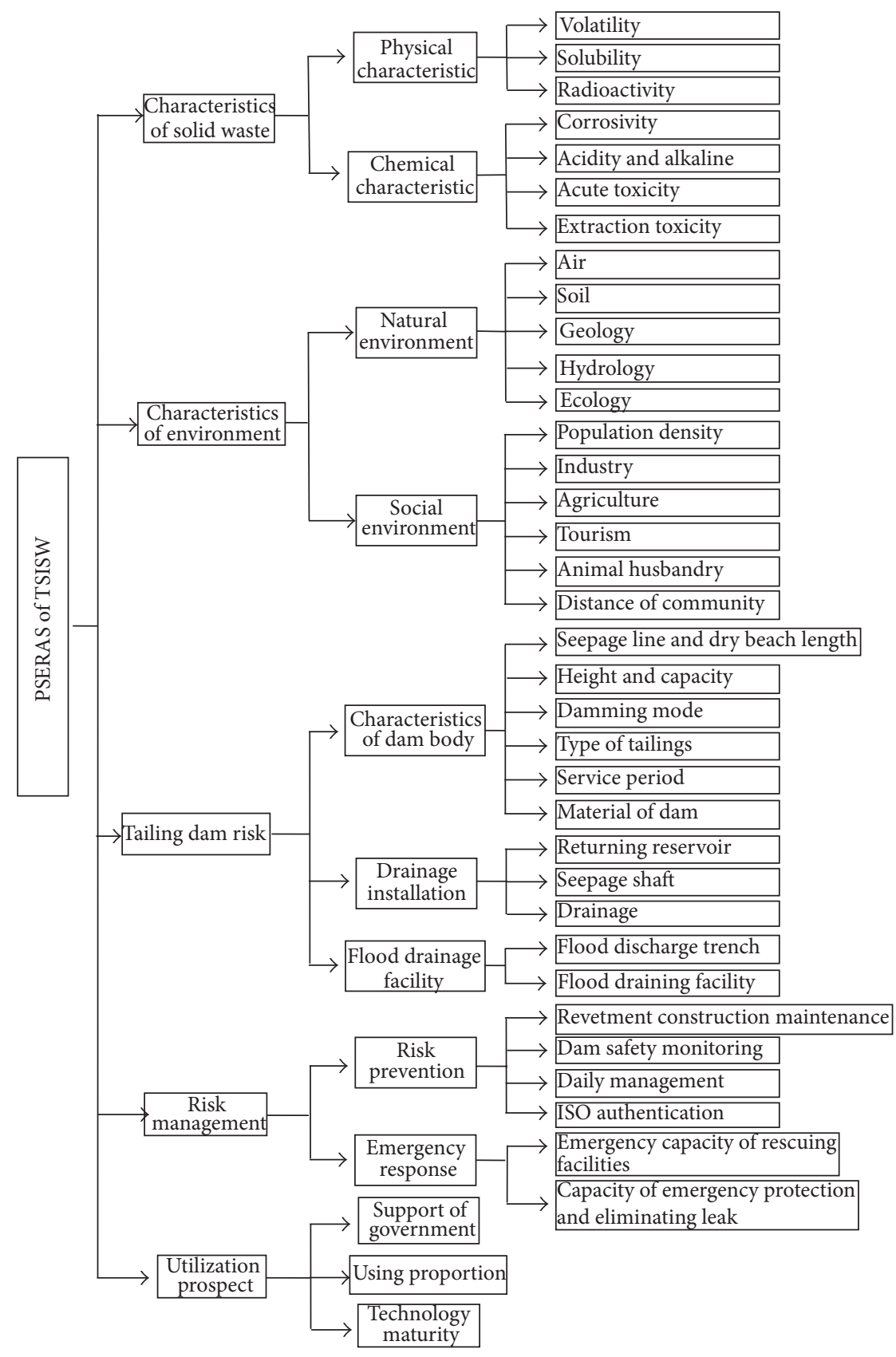

Figure 2

TABLE 2: The random consistency index (RI).

\begin{tabular}{lccccccccc}
\hline Size $(n)$ & 1 & 2 & 3 & 4 & 5 & 6 & 7 & 8 & 9 \\
\hline RI & 0.00 & 0.00 & 0.58 & 0.90 & 1.12 & 1.24 & 1.32 & 1.41 & 1.45 \\
\hline
\end{tabular}

the evaluation requirements for environmental risk assessment methods.

\section{New Risk Assessment Approach}

The current environmental risk assessment system (ERAS) is an integrated risk assessment, which considers all of the possible factors that affect the environmental risks due to pollution from PG tailing dams.

The main problem of ERAS for PG tailing dams is the integrated assessment of information from many different pollution sources, including quantitative and qualitative data. Therefore, it is necessary to develop detailed assessment methods based on the risk characteristics. Several methods 
TABLE 3: Linguistic variables and trapezoidal fuzzy numbers for the evaluation.

\begin{tabular}{lc}
\hline Linguistic variables & Trapezoidal fuzzy numbers \\
\hline Very poor & $(0,1,2,3)$ \\
Poor & $(1,2,3,4)$ \\
Medium & $(3,4,5,6)$ \\
Good & $(5,6,7,8)$ \\
Very good & $(7,8,9,10)$ \\
\hline
\end{tabular}

have been developed for risk assessment, including life cycle assessment (LCA), safety check list (SCL), probabilistic risk assessment (PRA), and the analytic hierarchy process (AHP). AHP is one of the most widely used assessment methods. AHP is based on the premise that decision-making related to complicated problems can be handled using a hierarchical structure that transforms complexity into a simple and comprehensible problem $[10,11]$. AHP has a wide range of applications, but the conventional AHP approach may not fully reflect the style of human thinking. For example, human judgment is usually represented as accurate numbers in AHP, but decision-makers usually feel more confident about giving interval judgments, rather than expressing their judgments as numeric values in actual situations $[12,13]$. Therefore, AHP and fuzzy logic are used as tools to handle problems where there is high complexity, such as environmental and uncertain data. AHP can support environmental decisionmakers by providing quantitative results and this ERAS approach can be applied to PG tailing dams.

In addition, the environmental supervision of industrial solid waste is a tremendous responsibility. Thus, the establishment of ERAS for PG tailing dams is very important for solid waste management and technology systems. Due to the characteristic requirements of ERAS for PG tailing dams, fuzzy logic and AHP can be combined to provide a more comprehensive analysis. This method may be extended to the development of an ERAS for solid waste management [13]. The proposed approach is shown in Figure 1.

2.1. Preliminary Stage. An abundance of risk data and information are related to PG tailing dams, so the establishment of an ERAS requires a range of experts from different disciplines with essential experience in construction. During the preliminary stage, the risk assessment group collected data related to risk, determined the risk criteria, identified the characteristics of tailings, obtained data related to tailing dams and the environments of tailing dams, analyzed the backgrounds of experts, identified potentially affected areas, and identified the final discharge media, and so forth.

\subsection{Establishment of a Factor Index (FI) Stage}

2.2.1. Establishment of the Factors in the FI Hierarchy. Many previous studies have shown that the AHP method can be used for multiobjective decision-making. The main sections of the overall hierarchy structure are based on the expert opinion and the qualitative analysis of the environment in
TABLE 4: List for investigation of the tailings of the XX phosphorus chemical industry in Yunnan.

\begin{tabular}{|c|c|}
\hline \multicolumn{2}{|l|}{ General information } \\
\hline Total storage capacity & 9.8 million $\mathrm{m}^{3}$ \\
\hline Starting date & 2003.06 \\
\hline Service period & 14.86 years \\
\hline Type of tailings & Valley Type \\
\hline Dam height & $45 \mathrm{~m}$ \\
\hline Storage capacity & $8639737 t$ \\
\hline Damming mode & Upstream tailings dam \\
\hline Comprehensive utilization & $6.84 \times 10^{5} \mathrm{t}$ \\
\hline Disposed quantity & $1.15 \times 10^{7} \mathrm{t}$ \\
\hline \multicolumn{2}{|l|}{$\begin{array}{l}\text { Physical-chemical analysis of } \\
\text { phosphogypsum }\end{array}$} \\
\hline Element & Content (\%) \\
\hline Water content & 24.20 \\
\hline $\mathrm{CaO}$ & 27.8 \\
\hline $\mathrm{Fe}_{2} \mathrm{O}_{3}$ & 0.10 \\
\hline $\mathrm{Al}_{2} \mathrm{O}_{3}$ & 0.53 \\
\hline $\mathrm{MgO}$ & 0.05 \\
\hline $\mathrm{K}_{2} \mathrm{O}$ & 0.13 \\
\hline $\mathrm{Na}_{2} \mathrm{O}$ & 0.13 \\
\hline $\mathrm{SO}_{4}^{-}$ & 33.9 \\
\hline $\mathrm{F}$ & 0.49 \\
\hline $\mathrm{SiO}_{2}$ & 11.85 \\
\hline $\mathrm{P}$ & 0.7 \\
\hline \multicolumn{2}{|l|}{ Extraction toxicity } \\
\hline Index & Unit (mg/L) \\
\hline $\mathrm{pH}$ & 5.73 \\
\hline $\mathrm{Cu}$ & $<0.02$ \\
\hline $\mathrm{Pb}$ & $<0.1$ \\
\hline $\mathrm{Zn}$ & 0.126 \\
\hline $\mathrm{Cr}$ & $<0.05$ \\
\hline $\mathrm{Cd}$ & $<0.005$ \\
\hline $\mathrm{Be}$ & $<0.005$ \\
\hline $\mathrm{Ba}$ & 4 \\
\hline $\mathrm{Ni}$ & $<0.04$ \\
\hline As & 0.0088 \\
\hline $\mathrm{Se}$ & 0.0004 \\
\hline $\mathrm{Ag}$ & $<0.01$ \\
\hline $\mathrm{Hg}$ & 0.0015 \\
\hline $\mathrm{Cr}^{6+}$ & $<0.004$ \\
\hline Cyanide & $<0.001$ \\
\hline Fluoride & 6.49 \\
\hline Methyl mercury & $<10 \mathrm{ng} / \mathrm{L}$ \\
\hline Ethyl mercury & $<20 \mathrm{ng} / \mathrm{L}$ \\
\hline
\end{tabular}

the study area. The ERAS used for PG tailing dams is shown in Figure 2. In this section, we will explain the details of each level. 
TABle 5: The scale of weight for experts.

\begin{tabular}{lcc}
\hline Expert & Background & Weight \\
\hline $\mathrm{E}_{1}$ & 50 years' experience in solid waste management & 0.23 \\
$\mathrm{E}_{2}$ & 50 years' experience in environment risk assessment & 0.23 \\
$\mathrm{E}_{3}$ & Mine senior engineer & 0.2 \\
$\mathrm{E}_{4}$ & 20 years' experience in tailings dam management & 0.18 \\
$\mathrm{E}_{5}$ & 10 years' experience in tailings dam management & 0.16 \\
\hline
\end{tabular}

At the first level in the hierarchy, the ERAS of PG tailing dams is the aim of the analysis. The second level includes the solid waste characteristics, environmental characteristics, tailing dam risk, risk management, and utilization prospects.

The solid waste characteristics refer to the characteristics of PG, which are used to evaluate the risk of the solid waste itself. The environmental characteristics include the geographical position, local hydrogeology conditions, and the aspects of the surrounding environment that are sensitive to tailings. These are significant factors, which are used to evaluate the level of environmental risk, and they are also the most closely related to the production activities of humans. The tailing dam risk refers to the tailing dam's interactions with its surroundings and human activities, which is used to measure the risk of security issues related to PG tailing dams. Risk management is related to the management and maintenance of PG tailing dams. The level of risk in this system is affected by risk management, and many accidents that occur in tailing dams are due to poor supervision. The utilization prospects refer to the comprehensive utilization of PG and government support.

At the third level, the characteristics of the solid waste are subfactors based on the physical and chemical characteristic. These factors are the inherent potential risks of the pollution source. The tailing dam risk factors comprise the characteristics of the dam body, drainage installation, and flood drainage facility. The risk management factors comprise risk prevention and emergency responses. The utilization prospect factors comprise government support and using mature technology, which are vital for this system. Thus, they are placed at the third level.

Solubility, volatility, and radioactivity were selected as the indexes for the physical characteristics at the fourth level. The solubility index reflects the water solubility of the tailings and the risk of leachate outflows, which are harmful to the environment. Radioactivity reflects the risk to the environment from the radioactivity for solid waste, such as radium-226 and its subfield, thorium-232 and its subfields, and potassium-40. Corrosiveness, acidity, alkalinity, acute toxicity, and extraction toxicity were used as subfactors for the chemical characteristics. Corrosiveness reflects the possibility of impermeable membranes being corroded by pollutants. The alkalinity reflects the extent of transfer in the environment. Therefore, the chemical characteristics are very important. The acute toxicity reflects the harmful effects of pollutants on organisms in the short-term, which directly reflects the harmful extent of pollutants. The extraction toxicity is an estimated index for solid wastes, which reflects the negative extent and transfer of pollutants after solid wastes have been leached by water.

The environmental characteristics are very important because they are related to the natural environment and the social environment. The natural environment in different regions has significant effects on the migration and transformation of pollutants. For example, acidic soils will increase heavy metal pollution in most cases, while different regional environments may have different levels of risk due to pollutants with respect to the possible loss of life and property. The natural environment includes the air, soil, geology, hydrology, and ecology. The social environment includes the population density, industry, agriculture, tourism, animal husbandry, and distances between communities.

The tailing dam risk reflects the direct impact on the environment based on its degree of stability. The stability of tailings is a security issue and an environmental issue because security risks can lead to environmental pollution. The factors related to the tailing dam risk include the seepage line and dry beach length, returning reservoir, height and capacity of tailings, drainage conditions, dam construction method, flood discharge trench, and the type of tailings.

Poor risk management is the main cause of accidents. Thus, normative operations and effective management will greatly reduce the likelihood of accidents. Risk management can be divided into risk prevention and emergency responses. Risk prevention considers the prevention capacity before the accident, including revetment construction maintenance, daily dam safety monitoring, and ISO authentication. Emergency responses reflect the handling after the accident, including the emergency capacity of rescue facilities and the capacity for emergency protection and leak elimination.

The utilization prospects are the most important of factors, because they indicate the current and future comprehensive utilization situations, while they also reflect the degree of recognition and the degree of support from governments for PG tailing dams.

2.2.2. Pairwise Comparisons of Factors. We conducted pairwise comparison of the factors at the same level based on their relative contributions to the ERAS. The pairwise comparisons used scores on a scale of 1-9, where 1 denoted factors with equal importance, and 3,5, 7, and 9 denoted factors with weak, strong, very strong, and the highest importance, respectively. The experts could award scores using a fuzzy scale if necessary. The scores of the pairwise comparisons were in different formats, so we had to convert them into a common form before the calculations. Standard trapezoidal 


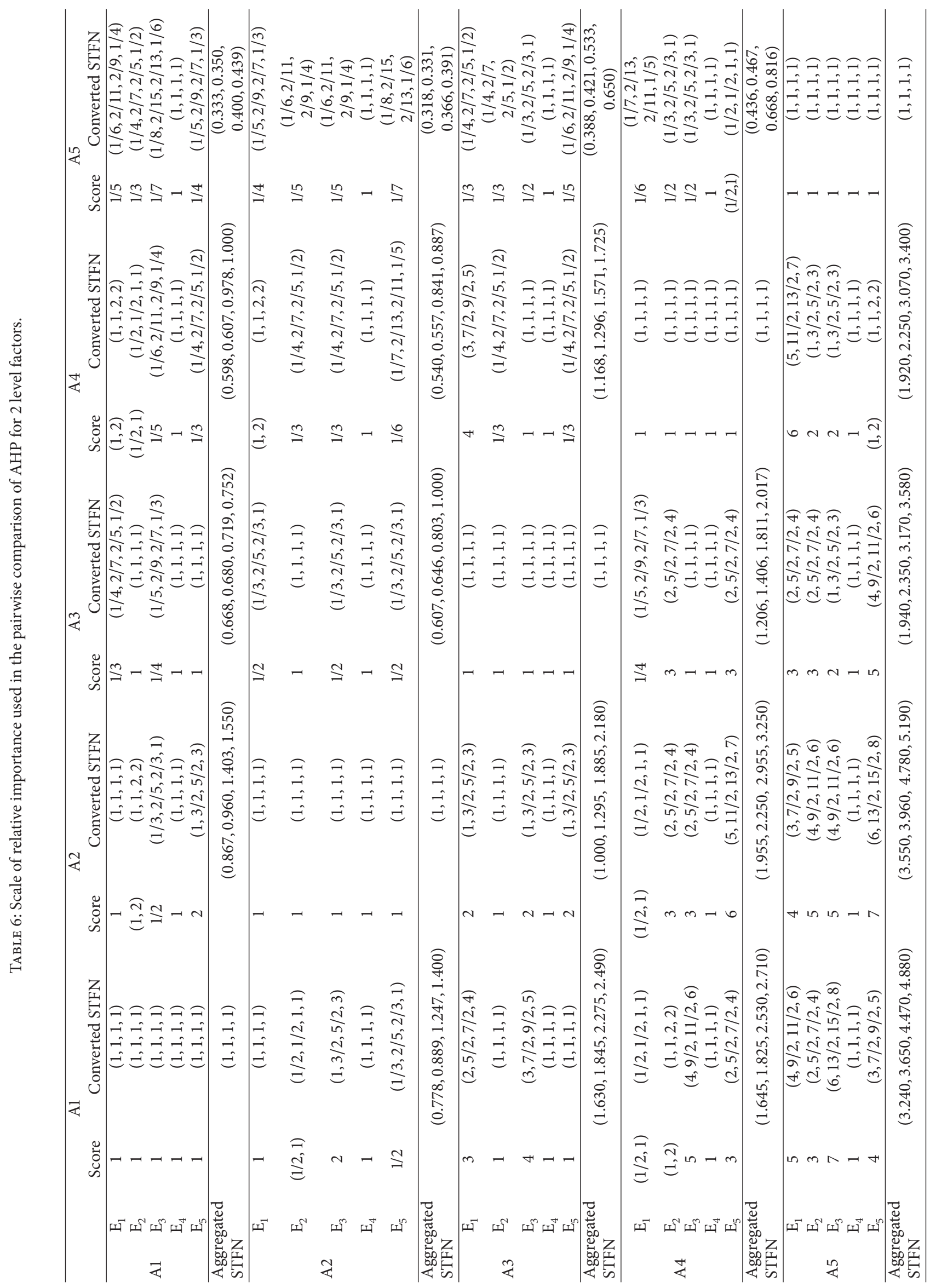


TABLE 7: Scale of relative importance used in the pairwise comparison of AHP for 3-level factors.

(a)

\begin{tabular}{lcc}
\hline & B1 & B2 \\
\hline B1 & $(1,1,1,1)$ & $(1 / 4,2 / 7,2 / 5,1 / 2)$ \\
B2 & $(2,5 / 2,7 / 2,4)$ & $(1,1,1,1)$ \\
\hline
\end{tabular}

(b)

\begin{tabular}{lcc}
\hline & B3 & B4 \\
\hline B3 & $(1,1,1,1)$ & $(1,1,1,1)$ \\
B4 & $(1,1,1,1)$ & $(1,1,1,1)$ \\
\hline
\end{tabular}

(c)

\begin{tabular}{cccc}
\hline & B5 & B6 & B7 \\
\hline B5 & $(1,1,1,1)$ & $(2,5 / 2,7 / 2,4)$ & $(2,5 / 2,7 / 2,4)$ \\
B6 & $(1 / 4,2 / 7,2 / 5,1 / 2)$ & $(1,1,1,1)$ & $(1,1,1,1)$ \\
B7 & $(1 / 4,2 / 7,2 / 5,1 / 2)$ & $(1,1,1,1)$ & $(1,1,1,1)$ \\
\hline
\end{tabular}

(d)

\begin{tabular}{ccc}
\hline & B8 & B9 \\
\hline B8 & $(1,1,1,1)$ & $(1,3 / 2,5 / 2,3)$ \\
B9 & $(1 / 3,2 / 5,2 / 3,1)$ & $(1,1,1,1)$ \\
\hline
\end{tabular}

(e)

\begin{tabular}{lccc}
\hline & B10 & B11 & B12 \\
\hline B10 & $(1,1,1,1)$ & $(1,1,1,1)$ & $(1,1,1,1)$ \\
B11 & $(1,1,1,1)$ & $(1,1,1,1)$ & $(1,1,1,1)$ \\
B12 & $(1,1,1,1)$ & $(1,1,1,1)$ & $(1,1,1,1)$ \\
\hline
\end{tabular}

fuzzy numbers (STFN) were also used in this study [11] and the conversion equation is shown in Table 1.

2.2.3. Establishment of the Pairwise Comparison Matrix. A matrix $A$ was constructed according for the pairwise comparisons using the following:

$$
\begin{gathered}
A=\left[\begin{array}{cccc}
\tilde{x}_{11} & \tilde{x}_{12} & \cdots & \tilde{x}_{1 n} \\
\tilde{x}_{21} & \tilde{x}_{22} & \cdots & \tilde{x}_{2 n} \\
\vdots & \vdots & \cdots & \vdots \\
\tilde{x}_{n 1} & \tilde{x}_{n 2} & \cdots & \tilde{x}_{n n}
\end{array}\right], \\
\tilde{x}_{i j}=\left(a_{i j}^{l}, a_{i j}^{m}, a_{i j}^{n}, a_{i j}^{s}\right), \\
\tilde{x}_{j i}=\tilde{x}_{i j}^{-1}=\left(a_{i j}^{s}, a_{i j}^{n}, a_{i j}^{m}, a_{i j}^{l}\right)^{-1},
\end{gathered}
$$

where $\tilde{x}_{i j}$ is the scale of $T_{i}$ comparing with $T_{j}$, while the scale is $\tilde{x}_{j i}$ when $T_{j}$ comparing with $T_{i}$.

2.2.4. Consistency Checking. Before calculating the weights of the index, the consistency of the comparison matrix must be checked. To check the consistency of the comparison matrix in an intuitive manner, the fuzzy numbers are first converted into matching crisp values using the following:

$$
x_{i j}=\frac{a_{i j}^{l}+2 * a_{i j}^{m}+2 * a_{i j}^{n}+a_{i j}^{s}}{6} .
$$

(a) Calculate the Largest Eigenvalue of the Matrix. The largest eigenvalue of the matrix can be calculated as follows [14]:

$$
A \cdot w=\lambda_{\max } \cdot w
$$

where $w$ is the principal eigenvector of the matrix.

(b) Consistency Check. The consistency of the comparison matrix can be determined using the consistency ratio (CR) as follows:

$$
\begin{gathered}
\mathrm{CI}=\frac{\lambda_{\max }-n}{n-1}, \\
\mathrm{CR}=\frac{\mathrm{CI}}{\mathrm{RI}},
\end{gathered}
$$

where $\mathrm{CI}$ is the consistency index, RI is the random index shown in Table 2 , and $n$ is the matrix size. As a rule, the consistency of the matrix is considered as acceptable only if $\mathrm{CR}<0.10$; otherwise the pairwise comparisons must be revised.

2.2.5. Calculate the Fuzzy Weight Vector. Based on the pairwise comparisons in matrix $A$, the weight vectors can be calculated using the following:

$$
\begin{gathered}
\alpha_{i}=\left[\prod_{j=1}^{n} a_{i j}^{l}\right]^{1 / n}, \\
\beta_{i}=\left[\prod_{j=1}^{n} a_{i j}^{m}\right]^{1 / n}, \\
\gamma_{i}=\left[\prod_{j=1}^{n} a_{i j}^{n}\right]^{1 / n}, \\
\delta_{i}=\left[\prod_{j=1}^{n} a_{i j}^{s}\right]^{1 / n}, \\
\delta=\sum_{i=1}^{n} \alpha_{i}, \\
\beta=\sum_{i=1}^{n} \delta_{i}, \\
\gamma=\sum_{i=1}^{n} \gamma_{i},
\end{gathered}
$$$$
\widetilde{w}_{i}=\left(\alpha_{i} \delta^{-1}, \beta_{i} \gamma^{-1}, \gamma_{i} \beta^{-1}, \delta_{i} \alpha^{-1}\right) \text {. }
$$ 
TABLE 8: Scale of relative importance used in the pairwise comparison of AHP for 4-level factors.

(a)

\begin{tabular}{lccc}
\hline & C1 & C2 & C3 \\
\hline C1 & $(1,1,1,1)$ & $(1 / 4,2 / 7,2 / 5,1 / 2)$ & $(1 / 7,2 / 13,2 / 11,1 / 5)$ \\
C2 & $(2,5 / 2,7 / 2,4)$ & $(1,1,1,1)$ & $(1 / 3,1 / 3,1 / 2,1 / 2)$ \\
C3 & $(5,11 / 2,13 / 2,7)$ & $(2,2,3,3)$ & $(1,1,1,1)$ \\
\hline
\end{tabular}

(b)

\begin{tabular}{lcccc}
\hline & C4 & C5 & C6 & C7 \\
\hline C4 & $(1,1,1,1)$ & $(1,3 / 2,5 / 2,3)$ & $(1 / 6,2 / 11,2 / 9,1 / 4)$ & $(1 / 5,2 / 9,2 / 7,1 / 3)$ \\
C5 & $(1 / 3,2 / 5,2 / 3,1)$ & $(1,1,1,1)$ & $(1 / 7,2 / 13,2 / 11,1 / 5)$ & $(1 / 6,2 / 11,2 / 9,1 / 4)$ \\
C6 & $(4,9 / 2,11 / 2,6)$ & $(5,11 / 2,13 / 2,7)$ & $(1,1,1,1)$ & $(1,1,2,2)$ \\
C7 & $(3,7 / 2,9 / 2,5)$ & $(4,9 / 2,11 / 2,6)$ & $(1 / 2,1 / 2,1,1)$ & $(1,1,1,1)$ \\
\hline
\end{tabular}

(c)

\begin{tabular}{lccccc}
\hline & C8 & C9 & C10 & C11 & C12 \\
\hline C8 & $(1,1,1,1)$ & $(1 / 6,2 / 11,2 / 9,1 / 4)$ & $(1 / 8,2 / 15,2 / 13,1 / 6)$ & $(1 / 6,2 / 11,2 / 9,1 / 4)$ & $(1 / 3,2 / 5,2 / 3,1)$ \\
C9 & $(4,9 / 2,11 / 2,6)$ & $(1,1,1,1)$ & $(1 / 3,2 / 5,2 / 3,1)$ & $(1,1,1,1)$ & $(2,5 / 2,7 / 2,4)$ \\
C10 & $(6,13 / 2,15 / 2,8)$ & $(1,3 / 2,5 / 2,3)$ & $(1,1,1,1)$ & $(1,3 / 2,5 / 2,3)$ & $(5,11 / 2,13 / 2,7)$ \\
C11 & $(4,9 / 2,11 / 2,6)$ & $(1,1,1,1)$ & $(1 / 3,2 / 5,2 / 3,1)$ & $(1,1,1,1)$ & $(2,5 / 2,7 / 2,4)$ \\
C12 & $(1,3 / 2,5 / 2,3)$ & $(1 / 4,2 / 7,2 / 5,1 / 2)$ & $(1 / 7,2 / 13,2 / 11,1 / 5)$ & $(1 / 4,2 / 7,2 / 5,1 / 2)$ & $(1,1,1,1)$ \\
\hline
\end{tabular}

(d)

\begin{tabular}{ccccccc}
\hline & $\mathrm{C} 13$ & $\mathrm{C} 14$ & $\mathrm{C} 15$ & $\mathrm{C} 16$ & $\mathrm{C} 17$ & $\mathrm{C} 18$ \\
\hline $\mathrm{C} 13$ & $(1,1,1,1)$ & $(5,11 / 2,13 / 2,7)$ & $(4,9 / 2,11 / 2,6)$ & $(4,9 / 2,11 / 2,6)$ & $(4,9 / 2,11 / 2,6)$ & $(1 / 4,2 / 7,2 / 5,1 / 2)$ \\
C14 & $(1 / 7,2 / 13,2 / 11,1 / 5)$ & $(1,1,1,1)$ & $(1 / 4,2 / 7,2 / 5,1 / 2)$ & $(1 / 4,2 / 7,2 / 5,1 / 2)$ & $(1 / 4,2 / 7,2 / 5,1 / 2)$ & $(1 / 9,2 / 17,2 / 15,1 / 7)$ \\
C15 & $(1 / 6,2 / 11,2 / 9,1 / 4)$ & $(2,5 / 2,7 / 2,4)$ & $(1,1,1,1)$ & $(1,1,1,1)$ & $(1,1,1,1)$ & $(1 / 7,2 / 13,2 / 11,1 / 5)$ \\
C16 & $(1 / 6,2 / 11,2 / 9,1 / 4)$ & $(2,5 / 2,7 / 2,4)$ & $(1,1,1,1)$ & $(1,1,1,1)$ & $(1,1,1,1)$ & $(1 / 7,2 / 13,2 / 11,1 / 5)$ \\
C17 & $(1 / 6,2 / 11,2 / 9,1 / 4)$ & $(2,5 / 2,7 / 2,4)$ & $(1,1,1,1)$ & $(1,1,1,1)$ & $(1,1,1,1)$ & $(1 / 7,2 / 13,2 / 11,1 / 5)$ \\
C18 & $(2,5 / 2,7 / 2,4)$ & $(7,15 / 2,17 / 2,9)$ & $(5,11 / 2,13 / 2,7)$ & $(5,11 / 2,13 / 2,7)$ & $(5,11 / 2,13 / 2,7)$ & $(1,1,1,1)$ \\
\hline
\end{tabular}

(e)

\begin{tabular}{lcccccc}
\hline & C19 & C20 & C21 & C22 & C23 & C24 \\
\hline C19 & $(1,1,1,1)$ & $(4,9 / 2,11 / 2,6)$ & $(2,5 / 2,7 / 2,4)$ & $(4,9 / 2,11 / 2,6)$ & $(4,9 / 2,11 / 2,6)$ & $(2,5 / 2,7 / 2,4)$ \\
C20 & $(1 / 6,2 / 11,2 / 9,1 / 4)$ & $(1,1,1,1)$ & $(1 / 4,2 / 7,2 / 5,1 / 2)$ & $(1,1,1,1)$ & $(1,1,1,1)$ & $(1 / 4,2 / 7,2 / 5,1 / 2)$ \\
C21 & $(1 / 4,2 / 7,2 / 5,1 / 2)$ & $(2,5 / 2,7 / 2,4)$ & $(1,1,1,1)$ & $(2,5 / 2,7 / 2,4)$ & $(2,5 / 2,7 / 2,4)$ & $(1,1,1,1)$ \\
C22 & $(1 / 6,2 / 11,2 / 9,1 / 4)$ & $(1,1,1,1)$ & $(1 / 4,2 / 7,2 / 5,1 / 2)$ & $(1,1,1,1)$ & $(1,1,1,1)$ & $(1 / 4,2 / 7,2 / 5,1 / 2)$ \\
C23 & $(1 / 6,2 / 11,2 / 9,1 / 4)$ & $(1,1,1,1)$ & $(1 / 4,2 / 7,2 / 5,1 / 2)$ & $(1,1,1,1)$ & $(1,1,1,1)$ & $(1 / 4,2 / 7,2 / 5,1 / 2)$ \\
C24 & $(1 / 4,2 / 7,2 / 5,1 / 2)$ & $(2,5 / 2,7 / 2,4)$ & $(1,1,1,1)$ & $(2,5 / 2,7 / 2,4)$ & $(2,5 / 2,7 / 2,4)$ & $(1,1,1,1)$ \\
\hline
\end{tabular}

(f)

\begin{tabular}{lccc}
\hline & C25 & C26 & C27 \\
\hline C25 & $(1,1,1,1)$ & $(1,1,1,1)$ & $(1,3 / 2,5 / 2,3)$ \\
C26 & $(1,1,1,1)$ & $(1,1,1,1)$ & $(1,3 / 2,5 / 2,3)$ \\
C27 & $(1 / 3,2 / 5,2 / 3,1)$ & $(1 / 3,2 / 5,2 / 3,1)$ & $(1,1,1,1)$ \\
\hline
\end{tabular}

(g)

C28 C29

\begin{tabular}{llr}
\hline C28 & $(1,1,1,1)$ & $(1,1,1,1)$ \\
C29 & $(1,1,1,1)$ & $(1,1,1,1)$ \\
\hline
\end{tabular}


(h)

\begin{tabular}{lcccc}
\hline & C30 & C31 & C32 & C33 \\
\hline C30 & $(1,1,1,1)$ & $(1 / 4,2 / 7,2 / 5,1 / 2)$ & $(1 / 5,2 / 9,2 / 7,1 / 3)$ & $(1 / 6,2 / 11,2 / 9,1 / 4)$ \\
C31 & $(2,5 / 2,7 / 2,4)$ & $(1,1,1,1)$ & $(1 / 3,2 / 5,2 / 3,1)$ & $(1 / 4,2 / 7,2 / 5,1 / 2)$ \\
C32 & $(3,7 / 2,9 / 2,5)$ & $(1,3 / 2,5 / 2,3)$ & $(1,1,1,1)$ & $(1 / 3,2 / 5,2 / 3,1)$ \\
C33 & $(4,9 / 2,11 / 2,6)$ & $(2,5 / 2,7 / 2,4)$ & $(1,3 / 2,5 / 2,3)$ & $(1,1,1,1)$ \\
\hline
\end{tabular}

(i)

\begin{tabular}{lcc}
\hline & C34 & C35 \\
\hline C34 & $(1,1,1,1)$ & $(1 / 4,2 / 7,2 / 5,1 / 2)$ \\
C35 & $(2,5 / 2,7 / 2,4)$ & $(1,1,1,1)$ \\
\hline
\end{tabular}

2.2.6. Defuzzification. The crisp value of $w_{i j}$ can be calculated using defuzzification with the following:

$$
w_{i j}=\frac{\alpha_{i} \delta^{-1}+2 \beta_{i} \gamma^{-1}+2 \gamma_{i} \beta^{-1}+\delta_{i} \alpha^{-1}}{6} .
$$

\subsection{Calculate the Scores of the Evaluation Factors}

2.3.1. Scores of the Evaluation Factors and Calculating the Fuzzy Evaluation Vectors. Using the data, that is, field survey and sampling data, the fuzzy evaluation vector of a specific factor is calculated as follows. Assume that there are $k$ decision-makers $E_{1}, E_{2}, \ldots, E_{k}$, and $n$ is attributed to $\tilde{f}_{1}, \tilde{f}_{2}, \ldots, \tilde{f}_{n}$. Convert the values into STFN, as shown in Table 3.

2.3.2. Construct the Fuzzy Evaluation Matrix. The evaluation value $\overline{\widetilde{f}}_{i}$ of the attribute $\widetilde{f}_{i}$ given by the decision-making group can be obtained as follows:

$$
\begin{gathered}
\tilde{f}_{i}=\left(f_{i}^{l}, f_{i}^{m}, f_{i}^{n}, f_{i}^{s}\right), \\
\overline{\tilde{f}}_{i}=\frac{1}{k} \sum_{i=1}^{k} \tilde{f}_{i} .
\end{gathered}
$$

2.4. Calculate the Evaluation Result. Calculate the risk magnitude (RM) using the following:

$$
\mathrm{RM}=w_{i j} \cdot \overline{\tilde{f}}_{i}
$$

\section{Case Study}

3.1. Preliminary Step. The necessary information collected in the preliminary step by the risk assessment group for a specific test case scenario is summarized in Table 4 .

3.2. Establishment of the FI Stage. Five highly qualified experts in the subject area were selected to form a risk assessment group and they performed the risk assessment using the proposed methodology. Each risk factor was evaluated at the different levels of the FI hierarchy by the experts who awarded scores. Different experts had different weight (Table 5) and they provided precise numerical values, linguistic terms, numerical value ranges, or a fuzzy number based on their knowledge and the information available. These evaluations were converted into STFNs as shown in Table 1 and (6)-(14).

3.2.1. Secondary Indices. Five experts graded the secondary indices (solid waste characteristics, environmental characteristics, tailing dam risk, risk management, and usage) in a pairwise manner according to Table 1 to produce Table 6.

3.2.2. Tertiary Indices. Experts from different fields graded the tertiary indices with which they were familiar in a pairwise manner to produce Table 7.

3.2.3. Quaternary Indices. Experts from different fields graded the quaternary indices with which they were familiar and the results are shown in Table 8 .

3.2.4. Matrix Creation and Uniformity Checking. A matrix was created using (1)-(5) and Table 2, and the uniformity of the grades was checked. In this case, $C R<0.10$, which demonstrated the uniformity of the grades.

3.2.5. Fuzzy Weight Calculation and Fuzzy Solving. The fuzzy weights were calculated and a fuzzy matrix was produced using (6)-(10). The results are shown in Table 9.

3.3. Risk Assessment Stage. Twenty experts graded the risk value according to Table 3 . The results are shown in Table 10.

3.4. Fuzzy Inference Stage. The assessments were made based on the data in Table 10, which were calculated using (16), and the results are shown in Table 11 .

\section{Discussion}

In this study, we developed an ERAS to evaluate the environmental risks of tailing dams produced by the phosphate fertilizer industry in Yunnan. Table 9 shows that five experts gave the most important weighting to the utilization prospects (A5) among the secondary indices. Thus, the utilization prospects had a direct relationship with the environmental risks of tailing dams. Risk management was also important. The leaks and inrushes that occur in tailing dams are caused by inappropriate management. To reduce environmental 
TABLE 9: The weights of the factors and subfactors.

\begin{tabular}{|c|c|c|}
\hline & Fuzzy weight vector & Defuzzified weights \\
\hline Characteristics of solid waste (A1) & $(0.081,0.091,0.139,0.161)$ & 0.112 \\
\hline Characteristics of environment (A2) & $(0.075,0.087,0.132,0.159)$ & 0.108 \\
\hline Tailing dam risk (A3) & $(0.117,0.143,0.216,0.264)$ & 0.176 \\
\hline Risk management (A4) & $(0.138,0.165,0.260,0.315)$ & 0.209 \\
\hline Utilization prospect (A5) & $(0.264,0.323,0.487,0.580)$ & 0.395 \\
\hline Physical characteristic (B1) & $(0.185,0.214,0.299,0.369)$ & 0.256 \\
\hline Chemical characteristic (B2) & $(0.522,0.632,0.884,1.045)$ & 0.744 \\
\hline Natural environment (B3) & $(0.5,0.5,0.5,0.5)$ & 0.5 \\
\hline Social environment (B4) & $(0.5,0.5,0.5,0.5)$ & 0.5 \\
\hline Characteristics of dam body (B5) & $(0.386,0.487,0.730,0.885)$ & 0.598 \\
\hline Drainage installation (B6) & $(0.153,0.174,0.233,0.279)$ & 0.201 \\
\hline Flood drainage facility (B7) & $(0.153,0.174,0.233,0.279)$ & 0.201 \\
\hline Risk prevention (B8) & $(0.366,0.511,0.851,1.098)$ & 0.650 \\
\hline Emergency response (B9) & $(0.211,0.264,0.440,0.634)$ & 0.350 \\
\hline Support of government (B10) & $(1 / 3,1 / 3,1 / 3,1 / 3)$ & $1 / 3$ \\
\hline Using proportion (B11) & $(1 / 3,1 / 3,1 / 3,1 / 3)$ & $1 / 3$ \\
\hline Technology maturity (B12) & $(1 / 3,1 / 3,1 / 3,1 / 3)$ & $1 / 3$ \\
\hline Volatility (C1) & $(0.073,0.082,0.119,0.138)$ & 0.100 \\
\hline Solubility (C2) & $(0.195,0.218,0.343,0.375)$ & 0.274 \\
\hline Radioactivity (C3) & $(0.481,0.516,0.765,0.822)$ & 0.626 \\
\hline Corrosivity (C4) & $(0.065,0.080,0.134,0.161)$ & 0.104 \\
\hline Acidity and alkaline (C5) & $(0.046,0.053,0.086,0.107)$ & 0.068 \\
\hline Acute toxicity (C6) & $(0.323,0.361,0.615,0.687)$ & 0.470 \\
\hline Extraction toxicity (C7) & $(0.239,0.271,0.472,0.531)$ & 0.358 \\
\hline Air (C8) & $(0.039,0.046,0.073,0.094)$ & 0.053 \\
\hline Soil (C9) & $(0.127,0.152,0.351,0.443)$ & 0.230 \\
\hline Geology $(\mathrm{C} 10)$ & $(0.172,0.231,0.661,0.815)$ & 0.403 \\
\hline Hydrology (C11) & $(0.127,0.152,0.351,0.443)$ & 0.230 \\
\hline Ecology (C12) & $(0.047,0.061,0.125,0.161)$ & 0.084 \\
\hline Population density (C13) & $(0.223,0.255,0.332,0.379)$ & 0.291 \\
\hline Industry (C14) & $(0.031,0.035,0.049,0.060)$ & 0.043 \\
\hline Agriculture (C15) & $(0.071,0.079,0.099,0.112)$ & 0.088 \\
\hline Tourism (C16) & $(0.071,0.079,0.099,0.112)$ & 0.088 \\
\hline Animal husbandry (C17) & $(0.071,0.079,0.099,0.112)$ & 0.088 \\
\hline Distance of community (C18) & $(0.296,0.346,0.464,0.537)$ & 0.402 \\
\hline Seepage line and dry beach length (C19) & $(0.270,0.339,0.514,0.631)$ & 0.417 \\
\hline Height and capacity (C20) & $(0.050,0.058,0.083,0.102)$ & 0.069 \\
\hline Damming mode (C21) & $(0.120,0.151,0.232,0.289)$ & 0.188 \\
\hline Type of tailings (C22) & $(0.050,0.058,0.083,0.102)$ & 0.069 \\
\hline Service period (C23) & $(0.050,0.058,0.083,0.102)$ & 0.069 \\
\hline Material of dam (C24) & $(0.120,0.151,0.232,0.289)$ & 0.188 \\
\hline Returning reservoir $(\mathrm{C} 25)$ & $(0.257,0.329,0.479,0.581)$ & 0.390 \\
\hline Seepage shaft (C26) & $(0.257,0.329,0.479,0.581)$ & 0.390 \\
\hline Drainage $(\mathrm{C} 27)$ & $(0.124,0.156,0.269,0.403)$ & 0.220 \\
\hline Flood discharge trench (C28) & $(0.5,0.5,0.5,0.5)$ & 0.5 \\
\hline Flood draining facility (C29) & $(0.5,0.5,0.5,0.5)$ & 0.5 \\
\hline Revetment construction maintenance (C30) & $(0.046,0.058,0.093,0.125)$ & 0.073 \\
\hline Dam safety monitoring (C31) & $(0.098,0.129,0.229,0.328)$ & 0.175 \\
\hline Daily management (C32) & $(0.153,0.212,0.386,0.543)$ & 0.291 \\
\hline ISO authentication (C33) & $(0.258,0.357,0.614,0.804)$ & 0.461 \\
\hline Emergency capacity of rescuing facilities (C34) & $(0.185,0.214,0.299,0.369)$ & 0.256 \\
\hline Capacity of emergency protection and eliminating leak (C35) & $(0.522,0.632,0.884,1.045)$ & 0.744 \\
\hline
\end{tabular}


TABLE 10: The summarization of the initial date of the evaluation for the 4-level factors.

\begin{tabular}{|c|c|c|c|c|c|}
\hline & VP & $\mathrm{P}$ & $\mathrm{M}$ & $\mathrm{G}$ & VG \\
\hline $\mathrm{Cl}$ & 0 & 3 & 11 & 5 & 1 \\
\hline $\mathrm{C} 2$ & 1 & 3 & 7 & 8 & 1 \\
\hline C3 & 0 & 2 & 5 & 10 & 3 \\
\hline $\mathrm{C} 4$ & 3 & 10 & 5 & 2 & 0 \\
\hline C5 & 2 & 11 & 6 & 1 & 0 \\
\hline C6 & 1 & 4 & 8 & 5 & 2 \\
\hline C7 & 0 & 1 & 7 & 11 & 1 \\
\hline C8 & 0 & 3 & 9 & 8 & 0 \\
\hline C9 & 3 & 7 & 7 & 3 & 0 \\
\hline $\mathrm{C} 10$ & 5 & 10 & 5 & 0 & 0 \\
\hline C11 & 1 & 4 & 10 & 3 & 2 \\
\hline $\mathrm{C} 12$ & 1 & 1 & 8 & 7 & 3 \\
\hline $\mathrm{C} 13$ & 1 & 1 & 8 & 8 & 2 \\
\hline $\mathrm{C} 14$ & 1 & 2 & 10 & 2 & 1 \\
\hline $\mathrm{C} 15$ & 0 & 3 & 6 & 9 & 2 \\
\hline $\mathrm{C} 16$ & 0 & 0 & 8 & 8 & 4 \\
\hline $\mathrm{C} 17$ & 0 & 2 & 9 & 7 & 2 \\
\hline $\mathrm{C} 18$ & 1 & 2 & 5 & 9 & 3 \\
\hline $\mathrm{C} 19$ & 1 & 5 & 10 & 4 & 0 \\
\hline $\mathrm{C} 20$ & 1 & 4 & 11 & 4 & 0 \\
\hline $\mathrm{C} 21$ & 3 & 8 & 6 & 3 & 0 \\
\hline $\mathrm{C} 22$ & 1 & 3 & 12 & 3 & 1 \\
\hline $\mathrm{C} 23$ & 1 & 1 & 8 & 7 & 3 \\
\hline $\mathrm{C} 24$ & 2 & 6 & 10 & 1 & 1 \\
\hline $\mathrm{C} 25$ & 0 & 0 & 8 & 10 & 2 \\
\hline $\mathrm{C} 26$ & 0 & 1 & 8 & 9 & 2 \\
\hline $\mathrm{C} 27$ & 1 & 2 & 9 & 6 & 2 \\
\hline $\mathrm{C} 28$ & 1 & 2 & 10 & 6 & 1 \\
\hline C29 & 2 & 3 & 8 & 5 & 2 \\
\hline C30 & 1 & 1 & 6 & 10 & 2 \\
\hline C31 & 0 & 1 & 7 & 11 & 1 \\
\hline C32 & 0 & 1 & 6 & 12 & 1 \\
\hline C33 & 0 & 0 & 8 & 11 & 1 \\
\hline C34 & 1 & 1 & 6 & 10 & 2 \\
\hline C35 & 1 & 2 & 7 & 9 & 1 \\
\hline B10 & 1 & 2 & 10 & 7 & 0 \\
\hline B11 & 2 & 4 & 10 & 3 & 1 \\
\hline B12 & 1 & 3 & 11 & 4 & 1 \\
\hline
\end{tabular}

risks, it is necessary to apply standards and effective management, but the most important task is risk prevention. The ratios of the seepage line and the dry beach length were the major factors used to evaluate the stability of a dam. These were significant dam risk indicators. Acute toxicity reflected the degree of harm due to direct contamination. Radioactivity was also a necessary indicator for PG. Thus, the acute toxicity and radioactivity were given higher weightings than other factors. However, the geography, the population density, and the distance between communities were more important environmental characteristics.

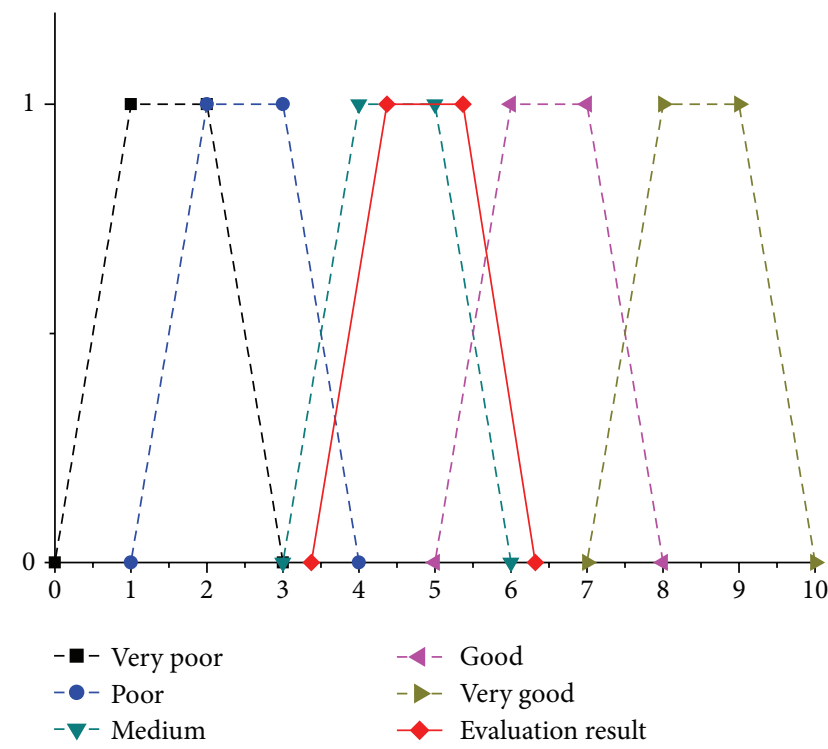

FIGURE 3: The membership functions of the five grades of the linguistic variables and the evaluation result.

(1) As shown in Figure 3, the environmental risk indices for the PG tailing dam were 3.371, 4.370, 5.370, and 6.321 , that is, medium, good. Thus, this tailing dam had some risk but could not pollute its surroundings.

(2) Table 11 shows that the area around this tailing dam had risk values of $1.25,2.25,3.25$, and 4.25 , which indicated the possible danger of environmental risk due to a pollution source based on the geography. In the next area, there was some risk based on the seepage line and dry beach length ratio, the height, capacity, and material of the dam and the damming mode. Thus, it is necessary to check, rectify, and reform this tailing dam and its surroundings to reduce risk and exclude hidden dangers.

This study established a method for evaluating the environmental risks of typical industrial solid wastes. We used fuzzy logic and AHP to determine the risk of a pollution source. This method is simple to use and can be quantified, so it is a practical management method for decision-makers.

\section{Conclusions}

The establishment of an ERAS for PG tailing dams will help to prevent PG tailing dams from affecting human health. Moreover, this method may help decision-makers who encounter unknown risks during the environmental management of PG tailing dams.

In the present study, we established an ERAS for PG tailing dams using AHP and fuzzy logic. A hierarchical evaluation index system was established, with five factors in the second level, 12 factors in the third level, and 35 factors in the fourth level. STFNs were used to determine the weights of the indices, and fuzzy weight vectors were calculated. The evaluation factors are scored and the fuzzy evaluation vectors 
TABLE 11: The evaluation results.

\begin{tabular}{|c|c|c|}
\hline & The fuzzy evaluating vectors & Rating \\
\hline Volatility (C1) & $(3.4,4.4,5.4,6.4)$ & $(\mathrm{M}, \mathrm{G})$ \\
\hline Solubility (C2) & $(3.55,4.55,5.55,6.55)$ & $(\mathrm{M}, \mathrm{G})$ \\
\hline Radioactivity (C3) & $(4.4,5.4,6.4,7.4)$ & $(\mathrm{M}, \mathrm{G})$ \\
\hline Corrosivity (C4) & $(1.75,2.75,3.75,4.75)$ & $(\mathrm{P}, \mathrm{M})$ \\
\hline Acidity and alkaline (C5) & $(1.7,2.7,3.7,4.7)$ & $(\mathrm{P}, \mathrm{M})$ \\
\hline Acute toxicity (C6) & $(3.35,4.35,5.35,6.35)$ & $(\mathrm{M}, \mathrm{G})$ \\
\hline Extraction toxicity $(\mathrm{C} 7)$ & $(4.2,5.2,6.2,7.2)$ & $(\mathrm{M}, \mathrm{G})$ \\
\hline Air (C8) & $(3.5,4.5,5.5,6.5)$ & $(\mathrm{M}, \mathrm{G})$ \\
\hline Soil (C9) & $(2.15,3.15,4.15,3.95)$ & $(\mathrm{P}, \mathrm{M})$ \\
\hline Geology (C10) & $(1.25,2.25,3.25,4.25)$ & $(\mathrm{P}, \mathrm{M})$ \\
\hline Hydrology (C11) & $(3.15,4.15,5.15,6.15)$ & $(\mathrm{M}, \mathrm{G})$ \\
\hline Ecology (C12) & $(4.05,5.05,6.05,7.05)$ & $(\mathrm{M}, \mathrm{G})$ \\
\hline Population density (C13) & $(3.95,4.95,5.95,6.95)$ & $(\mathrm{M}, \mathrm{G})$ \\
\hline Industry (C14) & $(2.45,3.25,4.05,4.85)$ & $(\mathrm{P}, \mathrm{M})$ \\
\hline Agriculture (C15) & $(4,5,6,7)$ & $(\mathrm{M}, \mathrm{G})$ \\
\hline Tourism (C16) & $(4.6,5.6,6.6,7.6)$ & $(\mathrm{M}, \mathrm{G})$ \\
\hline Animal husbandry (C17) & $(3.9,4.9,5.9,6.9)$ & $(\mathrm{M}, \mathrm{G})$ \\
\hline Distance of community (C18) & $(4.15,5.15,6.15,7.15)$ & $(\mathrm{M}, \mathrm{G})$ \\
\hline Seepage line and dry beach length (C19) & $(2.75,3.75,4.75,5.75)$ & $(\mathrm{P}, \mathrm{M})$ \\
\hline Height and capacity (C20) & $(2.85,3.85,4.85,5.85)$ & $(\mathrm{P}, \mathrm{M})$ \\
\hline Damming mode (C21) & $(2.05,3.05,4.05,5.05)$ & $(\mathrm{P}, \mathrm{M})$ \\
\hline Type of tailings (C22) & $(3.05,4.05,5.05,6.05)$ & $(\mathrm{M}, \mathrm{G})$ \\
\hline Service period (C23) & $(4.05,5.05,6.05,7.05)$ & $(\mathrm{M}, \mathrm{G})$ \\
\hline Material of dam (C24) & $(2.4,3.4,4.4,5.4)$ & $(\mathrm{P}, \mathrm{M})$ \\
\hline Returning reservoir (C25) & $(4.4,5.4,6.4,7.4)$ & $(\mathrm{M}, \mathrm{G})$ \\
\hline Seepage shaft (C26) & $(4.2,5.2,6.2,7.2)$ & $(\mathrm{M}, \mathrm{G})$ \\
\hline Drainage $(\mathrm{C} 27)$ & $(3.65,4.65,5.65,6.65)$ & $(\mathrm{M}, \mathrm{G})$ \\
\hline Flood discharge trench (C28) & $(3.45,4.45,5.45,6.45)$ & $(\mathrm{M}, \mathrm{G})$ \\
\hline Flood draining facility (C29) & $(3.3,4.3,5.3,6.3)$ & $(\mathrm{M}, \mathrm{G})$ \\
\hline Revetment construction maintenance (C30) & $(4.15,5.15,6.15,7.15)$ & $(\mathrm{M}, \mathrm{G})$ \\
\hline Dam safety monitoring (C31) & $(4.2,5.2,6.2,7.2)$ & $(\mathrm{M}, \mathrm{G})$ \\
\hline Daily management (C32) & $(4.3,5.3,6.3,7.3)$ & $(\mathrm{M}, \mathrm{G})$ \\
\hline ISO authentication (C33) & $(4.3,5.3,6.3,7.3)$ & $(\mathrm{M}, \mathrm{G})$ \\
\hline Emergency capacity of rescuing facilities (C34) & $(4.15,5.15,6.15,5.35)$ & $(\mathrm{M}, \mathrm{G})$ \\
\hline Capacity of emergency protection and eliminating leak (C35) & $(3.75,4.75,5.75,6.75)$ & $(\mathrm{M}, \mathrm{G})$ \\
\hline Support of government (B10) & $(3.35,4.35,5.35,6.35)$ & $(\mathrm{M}, \mathrm{G})$ \\
\hline Using proportion (B11) & $(2.8,3.8,4.8,5.8)$ & $(\mathrm{P}, \mathrm{M})$ \\
\hline Technology maturity (B12) & $(3.15,4.15,5.15,6.15)$ & $(\mathrm{M}, \mathrm{G})$ \\
\hline Physical characteristic (B1) & $(4.067,5.067,6.067,7.067)$ & $(\mathrm{M}, \mathrm{G})$ \\
\hline Chemical characteristic (B2) & $(3.376,4.376,5.376,6.376)$ & $(\mathrm{M}, \mathrm{G})$ \\
\hline Natural environment (B3) & $(2.248,3.248,4.248,4.972)$ & $(\mathrm{P}, \mathrm{M})$ \\
\hline Social environment (B4) & $(4.023,5.015,6.006,6.997)$ & $(\mathrm{M}, \mathrm{G})$ \\
\hline Characteristics of dam body (B5) & $(2.670,3.670,4.670,5.670)$ & $(\mathrm{P}, \mathrm{M})$ \\
\hline Drainage installation (B6) & $(4.157,5.157,6.157,7.157)$ & $(\mathrm{M}, \mathrm{G})$ \\
\hline Flood drainage facility (B7) & $(3.375,4.375,5.375,6.375)$ & $(\mathrm{M}, \mathrm{G})$ \\
\hline Risk prevention (B8) & $(4.272,5.272,6.272,7.272)$ & $(\mathrm{M}, \mathrm{G})$ \\
\hline Emergency response (B9) & $(3.852,4.852,5.852,6.392)$ & $(\mathrm{M}, \mathrm{G})$ \\
\hline Characteristics of solid waste (A1) & $(3.553,4.553,5.553,6.553)$ & $(\mathrm{M}, \mathrm{G})$ \\
\hline Characteristics of environment (A2) & $(3.136,4.131,5.127,5.985)$ & $(\mathrm{M}, \mathrm{G})$ \\
\hline
\end{tabular}


TABLE 11: Continued.

\begin{tabular}{lcr}
\hline & The fuzzy evaluating vectors & Rating \\
\hline Tailing dam risk (A3) & $(3.111,4.111,5.111,6.111)$ & $(\mathrm{M}, \mathrm{G})$ \\
Risk management (A4) & $(4.125,5.125,6.125,6.964)$ & $(\mathrm{M}, \mathrm{G})$ \\
Utilization prospect (A5) & $(3.100,4.100,5.100,6.100)$ & $(\mathrm{M}, \mathrm{G})$ \\
\hline Final objective & $(3.371,4.370,5.370,6.321)$ & $(\mathrm{M}, \mathrm{G})$ \\
\hline
\end{tabular}

were calculated. Finally, a comprehensive solid waste index, environmental index, tailing dam index, risk management index, utilization prospect index, safety grade, and early warning grade were determined. A PG tailing dam was fed into the model to evaluate the work safety performance and determine the safety grade.

This methodology, which combines AHP and fuzzy logic, is a new scientific method for performing environmental risk assessments of PG tailing dams, which generates accurate and comprehensive evaluation results. The safety grade and early warning grade generated by the proposed ERAS method may become powerful tools for officials, managers, and evaluators of PG tailing dams.

\section{Disclosure}

The authors would like to declare that the work described was original research that has not been published previously in whole or in part. All the authors listed have approved the manuscript that is enclosed.

\section{Conflict of Interests}

No conflict of interest exits in the submission of this paper.

\section{Acknowledgments}

This research was financially supported by the Ministry of Environmental Protection of the People's Republic of China (Ministry of Environmental Protection, Public Welfare Project, Contract no. 201109034).

\section{References}

[1] J. Sun, C. L. Geng, Z. T. Zhang, and X. T. Wang, "Present situation of comprehensive utilization technology of industrial solid waste," Materials Review, vol. 11, no. 2, pp. 105-109, 2012.

[2] F. Papanicolaou, S. Antoniou, and I. Pashalidis, "Experimental and theoretical studies on physico-chemical parameters affecting the solubility of phosphogypsum," Journal of Environmental Radioactivity, vol. 100, no. 10, pp. 854-857, 2009.

[3] Canadian Council of Ministers of the Environment, A Framework For Ecological Risk Assessment: General Guidance, Canadian Council of Ministers of the Environment, Winnipeg, Canada, 1996.

[4] P. M. Chapman, "Ecological risk assessment (ERA) and hormesis," Science of the Total Environment, vol. 288, no. 1-2, pp. 131140, 2002.

[5] P. M. Chapman, F. Wang, C. R. Janssen, R. R. Goulet, and C. N. Kamunde, "Conducting ecological risk assessments of inorganic metals and metalloids: current status," Human and Ecological Risk Assessment, vol. 9, no. 4, pp. 641-697, 2003.

[6] K. R. Hayes, Best Practice and Current Practice in Ecological Risk Assessment For Genetically Modified Organisms, CSIRO Division of Marine Research, Hobart, 2004.

[7] US Environmental Protection Agency, Emissions, Monitoring and Analysis Division, Office of Air Quality Planning and Standard, Research triangle park, 1997.

[8] US Environmental Protection Agency, "Guidelines for ecological risk assessment," Federal Register, vol. 63, no. 93, pp. 2684626924, 1998.

[9] Y. Zhang, Y. Z. Wu, L. G. Zong, and X. Feng, "Health risk assessment: case study of a brownfield contaminated by POPs at Changzhou," Environmental Science and Technology, vol. 31, no. 7, pp. 1135-1140, 2008.

[10] E. Karami, "Appropriateness of farmers' adoption of irrigation methods: the application of the AHP model," Agricultural Systems, vol. 87, no. 1, pp. 101-119, 2006.

[11] W. J. Tian, J. Bai, H. M. Sun, and Y. G. Zhao, "Application of the analytic hierarchy process to a sustainability assessment of coastal beach exploitation: a case study of the wind power projects on the coastal beaches of Yancheng, China," Journal of Environmental Management, vol. 115, pp. 251-256, 2013.

[12] G. Zheng, N. Zhu, Z. Tian, Y. Chen, and B. Sun, "Application of a trapezoidal fuzzy AHP method for work safety evaluation and early warning rating of hot and humid environments," Safety Science, vol. 50, no. 2, pp. 228-239, 2012.

[13] E. Topuz, I. Talinli, and E. Aydin, "Integration of environmental and human health risk assessment for industries using hazardous materials: a quantitative multi criteria approach for environmental decision makers," Environment International, vol. 37, no. 2, pp. 393-403, 2011.

[14] Y. Yao, Z. Lian, S. Liu, and Z. Hou, "Hourly cooling load prediction by a combined forecasting model based on analytic hierarchy process," International Journal of Thermal Sciences, vol. 43, no. 11, pp. 1107-1118, 2004. 


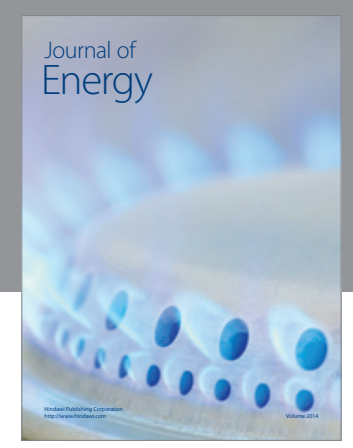

Journal of

Industrial Engineering
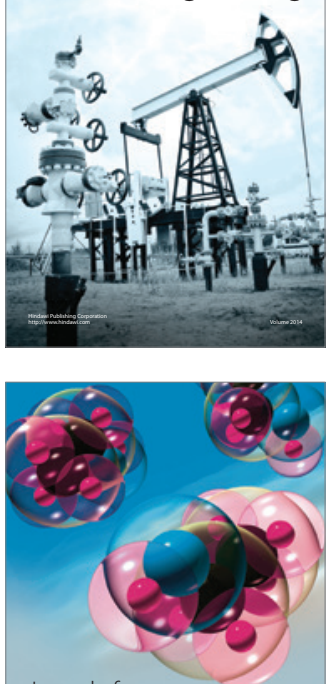

Fuels
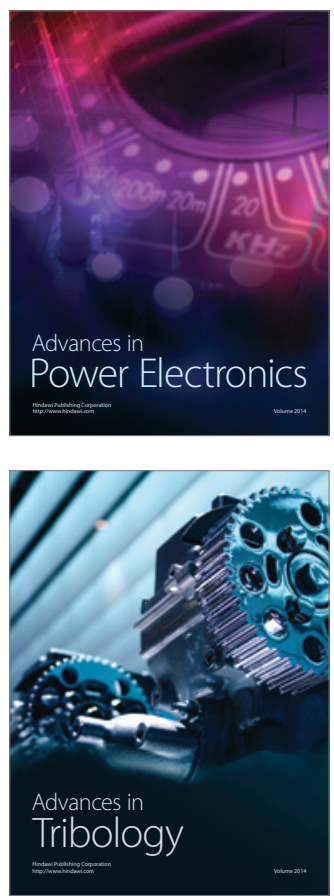

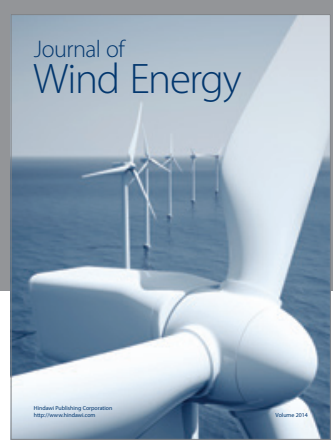

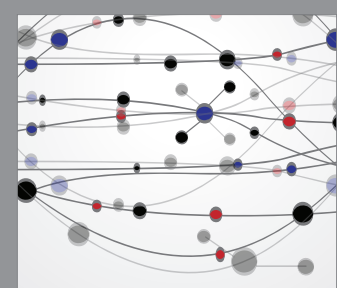

The Scientific World Journal

Submit your manuscripts at http://www.hindawi.com

Journal of

Structures
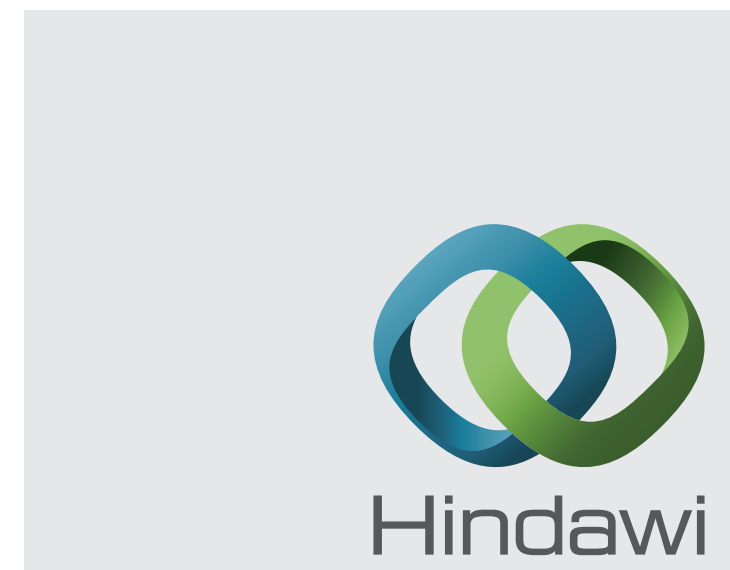

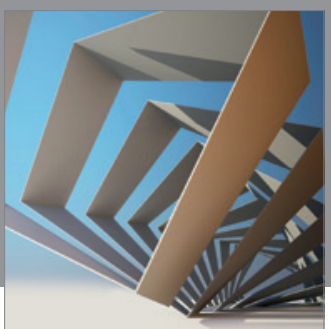

Rotating

Machinery
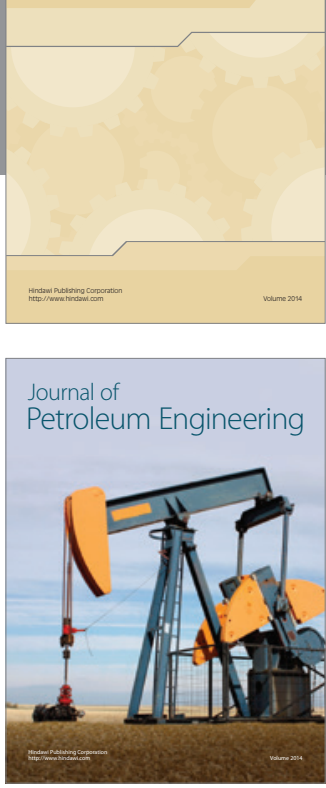

Journal of

Solar Energy
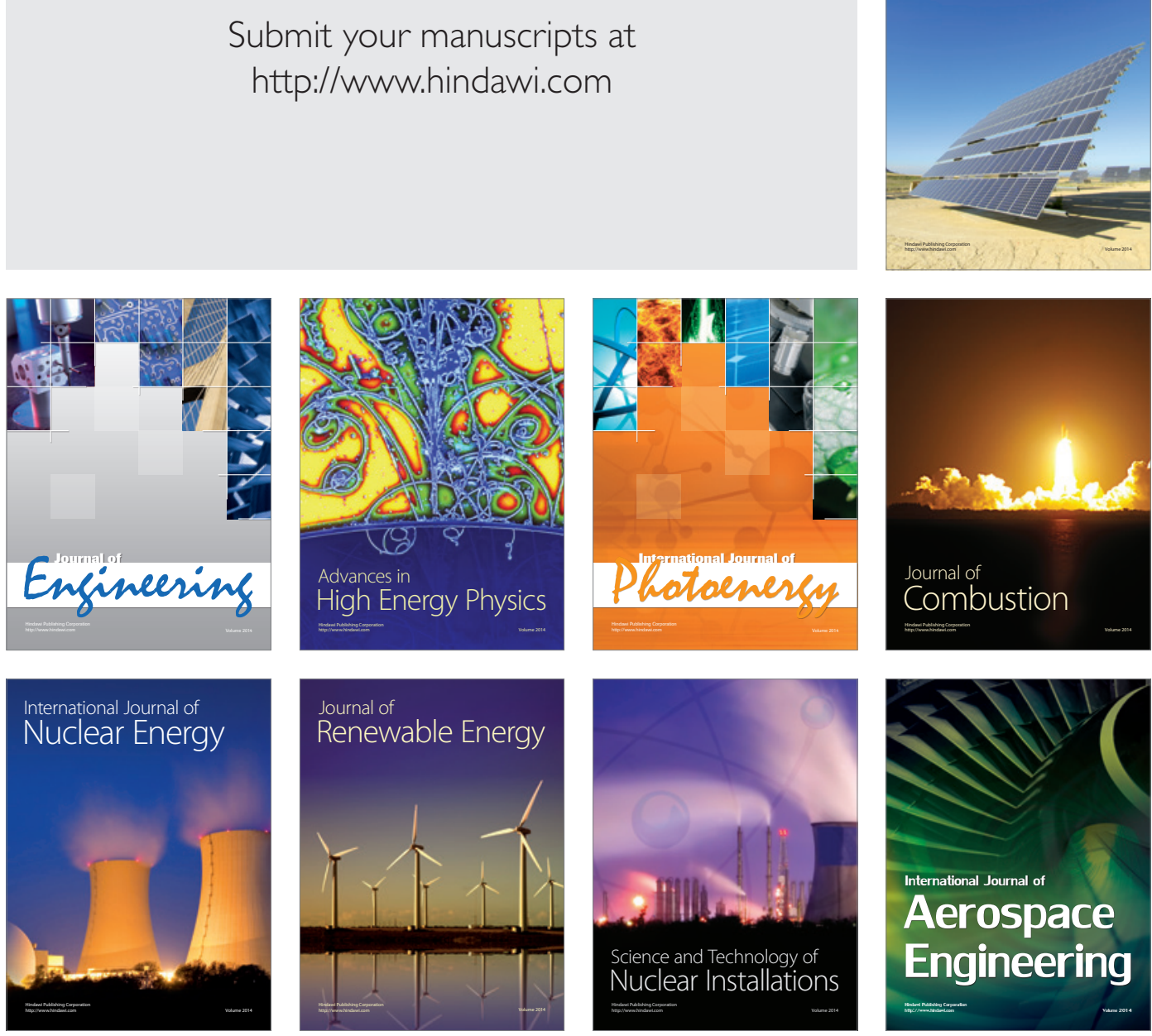